\title{
Architecture Students' Innovation Ability Training Multi-Dimensional Practice Platform Construction
}

\author{
Ming Zhou
}

\begin{abstract}
Department of Architectural Engineering, Jiangxi Science and Technology Normal University, NanChang, JiangXi, China
\end{abstract}

\begin{abstract}
.
\section{Introduction}

The architecture profession is very practical. In the teaching plan and curriculum setting, the importance of practical teaching to talent cultivation should be emphasized. In the teaching process, the students' practical ability and innovative ability should be taken as a key link. On the one hand, scientifically and rationally designing the practical teaching system and constructing the architecture curriculum practice platform will help students improve their design practice ability and innovation ability. On the other hand, they can enhance students' interest in the study and application of architectural design expertise. Exploring in the course of architecture, how to build a practical platform to strengthen students' practical ability and innovative spirit training is of great value for cultivating high-quality and innovative design talents.
\end{abstract}

The architecture major is very practical. In the teaching plan and curriculum setting, the importance of practical teaching to talent cultivation should be emphasized. Based on the analysis of the status quo of architecture practice teaching, this paper believes that the construction of multi-dimensional practice platform is a powerful guarantee to improve students' design practice ability and innovation ability. In addition to paying attention to the traditional practice teaching, the practice platform should also explore the construction of a practical platform under the cooperation of school-enterprise cooperation, BIM technology in the "Internet +" era, and the international platform model of architectural education.

Keywords: architecture, innovation, practice, platform construction

\section{The status quo of architecture practice teaching}

The 21st century is an era of knowledge-based economy in which education and science and technology are in-depth development and social competition is becoming increasingly fierce. This requires that our professional education in architecture should adapt to the needs of social development as soon as possible, and consider the talent training model at a higher level. An idea permeates the entire process of teaching and management. Many famous foreign universities attach great importance to cultivating college students' innovative ability through practical teaching. Not only do they set up relevant courses, but they also basically stipulate that students must obtain credits for practice. For example, the Massachusetts Institute of Technology clearly stipulates in the teaching plan that college students must participate in the innovation activities of scientific research practice from the lower grades; German higher engineering colleges also attach great importance to practical teaching links, in addition to completing relevant courses, but also to complete innovative design. And innovative practice teaching tasks. Undoubtedly, the current development of architecture education in China has made great progress, and has made great achievements in the training of talents, teaching plans, curriculum systems and teaching content reform. However, due to the influence of traditional architecture education, the architecture profession in China generally attaches importance to the teaching of simple knowledge, ignoring the phenomenon of innovation ability and practical ability training.

Taking the architecture major of our school as an example, since the beginning of the school, it has formed a relatively complete academic system, and its development status has a certain representativeness in the province. Over the years, the students majoring in architecture in our school have achieved outstanding results in various design competitions. The graduates have been hard-working and have received wide acclaim from employers. However, when we returned to the graduated students, we found that they generally reflected the two contents that were most lacking in college education. First, the innovative thinking training was not enough. If there is no innovative mind, it is difficult to become a leader in the design team. Characters, innovative thinking will determine the development space and height of a designer; second, the practical teaching in the university is out of touch with the current social development, and the practice links in ecological technology and digital technology are weak and difficult to achieve. High-end design talent. On the one hand, the content of the practice in the curriculum is not enough, and on the other hand, influenced by the graduate entrance examination, the study abroad exam and the job search, the practical effect of the professional internship of the design institute is also affected.

Although the architectural education of our school has always attached great importance to the practice of professional courses, it has not been able to integrate 
college students in all grades. All kinds of courses in architecture should reasonably arrange practical content around the teaching objectives to stimulate students' innovative thinking and improve students' practical ability. For example, in the first-year preliminary course of architectural design, students are required to do spatial composition models to train students' perceptions of architectural space, composition, color, etc. (Figure 1); the second-grade architectural design curriculum focuses on working models. Train students' perceptions of construction sites and volume; third-grade and above professionals combine different designs to create elaborate models to deepen understanding of various spatial combinations, changes and architectural details (Figure 2). In the relevant classroom teaching, you can also contact the construction site or constructive analysis of some building objects, understand the complexity of the building, and generate a correct understanding of the building. At the same time, you can use the node model and the physical construction training to let the students Have a deeper understanding of the architectural principles. To give full play to the role of understanding internships, surveying and internships, and production internships, it is necessary to formulate practical and practical internship plans based on the specific conditions of current building development. Through the university students' scientific research and innovation project, the university provides scientific research training platform for students, cultivates students' scientific research consciousness and teamwork spirit, and improves scientific research and practical innovation ability.

platform for practical teaching of architecture. traditional practice links include the practice links in each course, the practical teaching in the internship courses of all grades, the graduation design, and the cultivation of practical ability in the research and innovation projects of

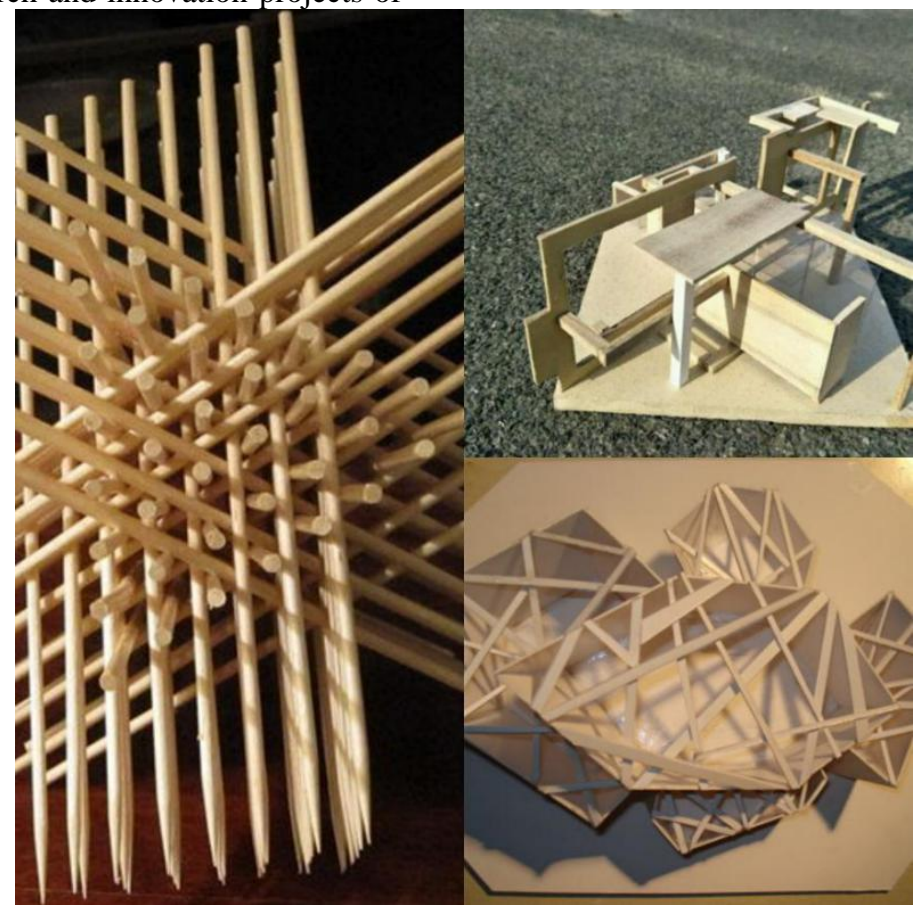

Figure 1 The practical work of spatial perception training 


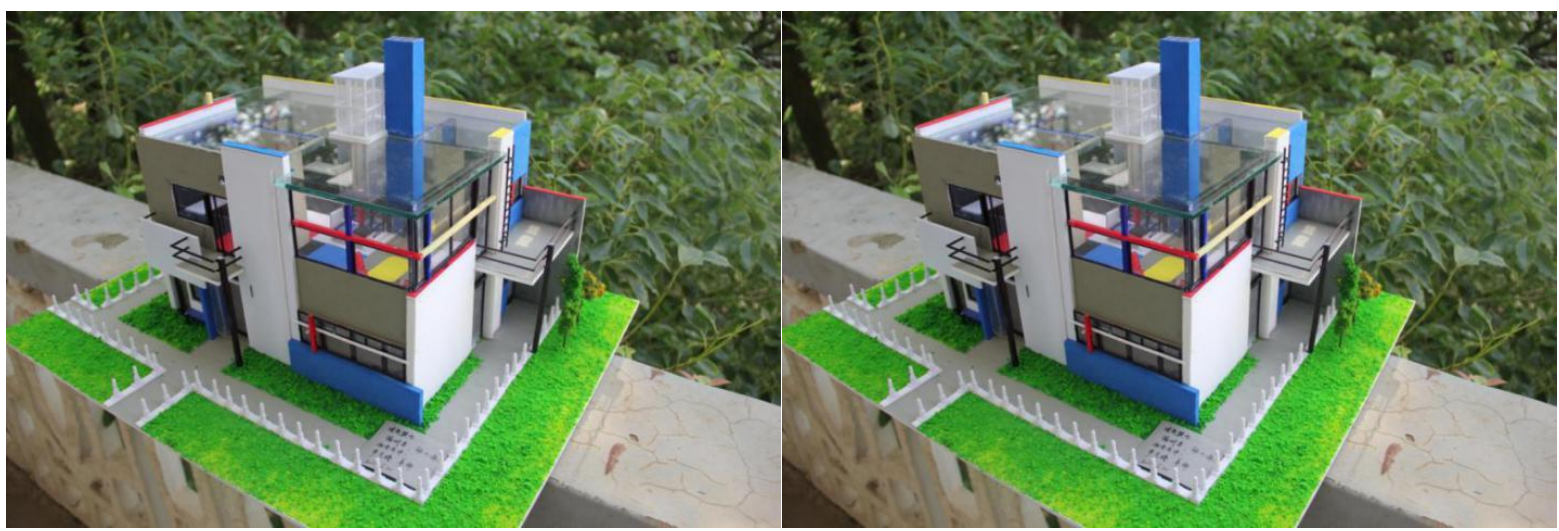

Figure 2 Fine model making practice works

\subsection{Practice teaching under the mode of school-enterprise cooperation}

"School-enterprise cooperation" means that through the cooperation between the school and related enterprises, the school can support each other in teaching and enterprise production, and cooperate with each other to finally obtain a talent-winning model of school-enterprise win-win. In fact, the school-enterprise cooperation model under the "production-study-research" teaching system has been explored many years ago at home and abroad. However, as a company, economic interests are always at the forefront, and as a school, training students is its ultimate goal. In the current school-enterprise cooperation process, schools and enterprises are often in a non-equivalent state: due to the important impact of economic benefits in actual projects, the cooperation between the two parties can easily evolve into the final goal of completing the project, and the project's role in teaching quality. It is difficult to assess. Therefore, in order to truly achieve a win-win result, it is necessary to fully understand the needs of the enterprise, and carefully design the project according to the actual situation of the enterprise project, and arrange the teaching plan and design progress. The school-enterprise cooperation model can be diversified, such as establishing a production base, regularly sending students to participate in actual engineering projects in the past; or taking the actual project of the enterprise into the classroom as a subject design graduation project, allowing students to have a real professional experience; The teaching method relies on the establishment of practical training centers and teaching bases by schools and enterprises. Teachers and enterprises maintain close contact with each other in order to conduct timely and rational research and design of topics. In this respect, the French design school has given us very good revelation after long-term practice. In the cooperation between schools and enterprises in France, the purpose of seeking cooperation in schools is not related to economic benefits. It is the purpose of obtaining good ideas and ideas, and improving the quality and connotation of enterprises. The cooperation with schools is a social responsibility. Schools have a duty to serve: such as technology, venues, and certain financial support. In the process of serving the enterprise, the school aims to serve the teaching and improve the quality of the course as the ultimate goal of cooperation. Therefore, the cooperation between the two sides has no strong economic benefit relationship, but a true partnership. Schools and enterprises are on an equal footing. School and enterprise are a kind of mutual service and mutual dependence. In the French school-enterprise cooperation, the curriculum instructors undertake tasks such as external coordination and liaison, curriculum organization, teaching quality control, and project progress. Although the cooperation projects will be carried out according to certain plans, they have greater flexibility and flexibility.

The ancient building survey shown in the figure (Fig. 3) is a practical project for cooperation between the school's architecture major and Jiangxi Jinshang Cultural Relics Protection Engineering Co., Ltd. and students' participation. The project is a survey of the ancient buildings on the Sanbao Street in Hekou Town, Shangshan County, Shangrao City. The project covers a wide area, the task is heavy, and the time is short. We sent 11 students to complete the surveying and mapping tasks in 20 days, and the enterprise solves the urgent needs of the students. They also got a practical opportunity to explore a feasible way for school-enterprise cooperation. 


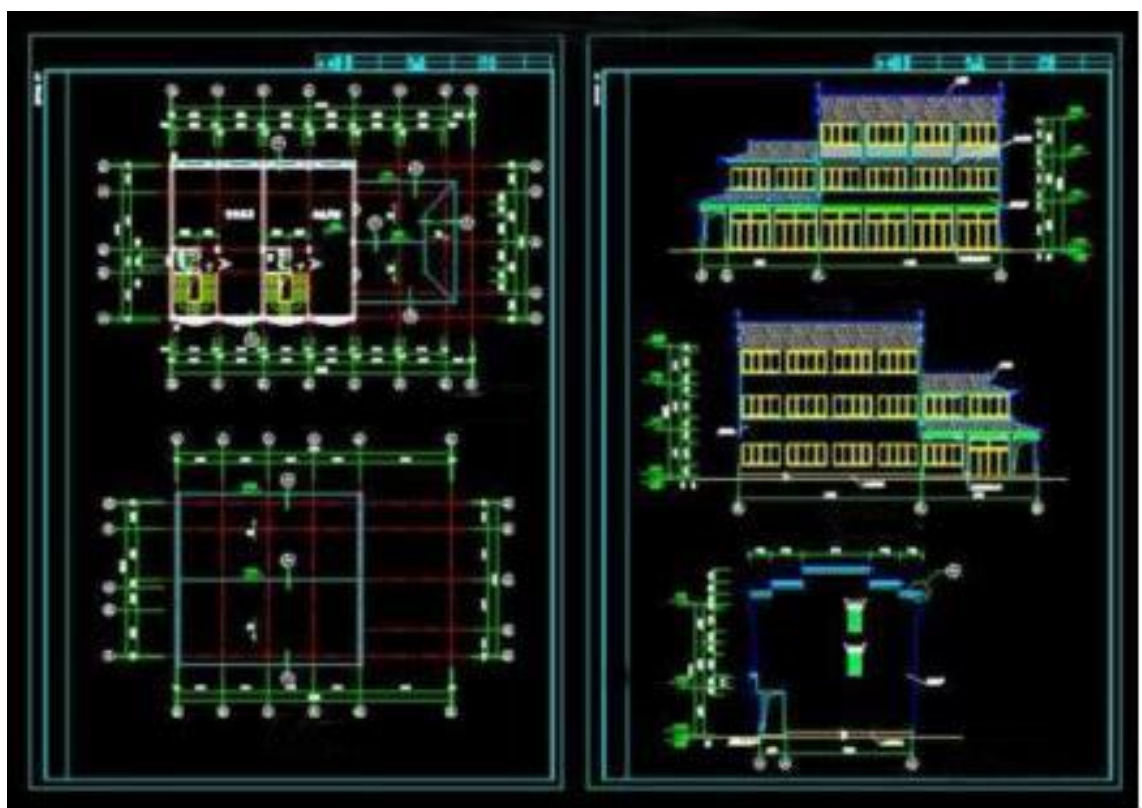

Figure 3: Practical works under the school-enterprise cooperation model

\subsection{Exploring the Teaching Practice of BIM Technology in the Age of "Internet +"}

Since the computer technology became more and more mature in the construction industry in the $1880 \mathrm{~s}$, in the field of architecture, both theoretical research and architectural practice have undergone earth-shaking changes and achieved great breakthroughs. In the teaching of architecture, with the rapid development of computer technology and the Internet, it has quietly entered the era of digital teaching. This change has profoundly changed the connotation, goals, means, and application scope of modern architecture.

In 2014, the media called the first year of Internet thinking, and in the two sessions in 2015, the "Internet +" action plan was formulated. So far, many industries are moving towards the "Internet + " model. The integration of the Internet and the construction industry has promoted the vigorous development of many emerging digital technologies in the construction industry. Virtual reality, building information models, and parametric design are all products of the combination of architectural disciplines and advanced digital technologies. The integration of new digital technologies and architectural disciplines requires not only high levels of experimental and technical conditions to support, but also the need to break through traditional teaching models and explore teaching methods that are more adaptive to the characteristics of this era.

Based on this, we have added the REVIT course to the curriculum, which is only the first step in the era of "Internet +" for architecture. At present, this teaching practice is constantly deepening with the advancement of BIM. Through this course, students can have a more systematic understanding of BIM digital technology, gradually master the method of remote collaborative work through ArchiCAD and BIMcloud platform, and cultivate students' ability and thinking mode of using BIM digital technology for program design.

Through the current teaching practice, we have made the following considerations for the establishment of the BIM digital technology architecture teaching system: BIM is the latest trend in the AEC industry. In today's increasingly competitive construction industry, the arrival of BIM technology is conducive to the development of new designs. And management methods are the core competitiveness in the construction field. However, the design theories and methods related to BIM are still in an exploratory stage. While teaching practice, we need to understand and master the latest international teaching trends in a timely manner. We should strengthen exchanges and learning with domestic and foreign counterparts in the field. The strengths of others, actively promote the application of BIM digital technology in architecture, and promote the development of teaching reform and practice of digital technology courses.

\subsection{Construction of the international platform for architectural education}

The field of architecture has placed great emphasis on cultivating the designer's depth of thinking and breadth of vision. The development of the era has raised the more challenging goal of cultivating the international vision of architects. For the cultivation of college students, we hope that they will The international vision not only stays at the collection and organization of information materials, but also through the experiential learning process, participatory field trips, face-to-face multi-country exchanges, gaining experience and inspiration from its design, often forming a better building. The teacher's international thinking and creative view. 
The advantages of building an international platform for architectural education are mainly reflected in the following two aspects:

\subsubsection{Diverse teaching model.}

The diversified teaching mode is not only the diversification of teaching forms, but also the diversification of design ideas and the opening of design results. In the teaching, the academic thoughts of architecture facing the world are emphasized. In the process of creating the same topic from different perspectives and using different methods, different countries' thinking modes and problem-solving ideas have produced different thinking modes of architectural creation, resulting in a "mixed blood" effect. In a complete project training, if the participating groups from different cultural backgrounds and different social positions can fully demonstrate their uniqueness, then these unique viewpoints, features, and techniques will form a process of mutual complementarity. A new, more sophisticated model. The diversified teaching model focuses on cultivating students' ability to discover problems and solve problems on their own, emphasizing the exchange of thoughts and methods for the future, rather than simply overlapping knowledge, so the diversified teaching model should have greater freedom. Sexuality and inclusiveness allow teachers and students to have flexible space for their own play, and the design results are diverse and open, and strive to select the best among the best.

\subsubsection{Internationalized reference platform.}

An internationalized reference platform is both a platform for learning and understanding the strengths of others, as well as an opportunity to showcase itself. The participating countries and institutions are able to grasp the latest developments in the construction discipline on the platform to achieve accurate self-positioning. International joint teaching is a complete design with a common project and a common standard, forming a holistic teaching structure that is mutually referenced and mutually promoted between countries, between schools, and between cultures. Only in internationalized The relevant teachers and students in the reference standard can relatively accurately locate themselves in the process of internationalization.

\section{CONCLUSION}

The practical teaching of architecture plays a very unique role in the cultivation of architectural talents. It is an important teaching measure to solve students' comprehensive ability, enhance students' interest in learning, integrate the knowledge of classroom abstract theory, and is also an effective method to cultivate innovative and intelligent talents. . At present, the demand for architectural design talents in the society is also comprehensive and multi-level. It is not enough to rely solely on the simple theoretical teaching in the classroom and the teaching internship in the school. Most economically oriented design companies urgently need a large number of high-level comprehensive qualities. They can master certain professional theoretical knowledge and strong design innovation ability. They can not only be familiar with the specific technical skills of their positions, but also understand the comprehensive design process. Sexual design talent. Study how to build a multidimensional practical platform for the cultivation of creative ability of architecture students to strengthen the cultivation of students' practical skills, break the traditional education mode, establish a new modern educational concept, find more suitable methods and modes for professional characteristics, and cultivate both Architectural talents with innovative and practical capabilities are of great significance.

\section{REFERENCES}

[1] Qiu Dehua.The construction and exploration of the practical teaching system of architecture in Suzhou University of Science and Technology[J].Higher Education of Architecture,2011,5:114-117.

[2] Zhou Chao.Workshop-French design teaches the effective mode of school-enterprise cooperation--A side note on the renovation project of the Illustrator Museum of Burgundy Art School[J].Journal of Suzhou Arts and Crafts Vocational College,20011.2:65-70.

[3] Qiu Wei, Nan Jun, Yuan Yixing. The Innovative Curriculum System of the Excellent Engineer Education and Training Program and Its Characteristics-Taking the Civil Engineering of Harbin Institute of Technology as an Example [J]. Heilongjiang Higher Education Research, 2015(1): 164-167.

[4] Liu Hui, Tan Gangyi. Rationality, Innovation and Experimental Spirit-Exploration and Practice of the Undergraduate Characteristic Teaching System of Huazhong University of Science and Technology [J]. Journal of Architecture, 2013 (2): 106-109. 